\title{
Central Baltic Sea herring: effect of environmental trends and fishery management
}

\author{
R. Aps ${ }^{1}$, M. Fetissov ${ }^{1}$, N. Holmgren ${ }^{2}$, N. Norrström ${ }^{2} \&$ S. Kuikka ${ }^{3}$ \\ ${ }^{1}$ Estonian Marine Institute, University of Tartu, Estonia \\ ${ }^{2}$ University of Skövde, Skövde, Sweden \\ ${ }^{3}$ University of Helsinki, Helsinki, Finland
}

\begin{abstract}
Uncertainty is an endemic condition of the Baltic Sea herring (Clupea harengus membras, L) fishery management. It is a condition exacerbated by the fishing fleet overcapacity and consequent exploitation of the herring stock at a level believed to be unsustainable. Some sources of uncertainty are mainly related to biology and fishing technique: the unsolved problem of herring assessment and management units, the recruitment-environment relationship and the reduction in mean weights-at-age, uncertain ageing of fish, the problem of unaccounted fishing mortality caused by the fish selection through the trawl net. Fishing fleet overcapacity is believed to be behind of the regulatory overfishing when setting the Total Allowable Catches (TACs) higher than the scientific advice (decision overfishing) and tolerating the extensive underreporting of catches (implementation overfishing). Two scenarios for the Central Baltic Sea herring fishery management options are constructed and the Bayesian networks are used to represent and update uncertainties encountered in the process of the management related situation assessment. First scenario represents the current status of the fishery management resulting in fishing mortality (F) higher than $\mathrm{F}_{\mathrm{MSY}}$ - the fishing mortality that corresponds to the Maximum Sustainable Yield (MSY). The second scenario demonstrates the assumed potential impact of economic incentives (e.g. zoning, individual transferable quotas (ITQs), territorial use rights etc.) on the reduction of excessive fishing capacity and bringing actual fishing mortality closer to $\mathrm{F}_{\mathrm{MSY}}$.

Keywords: Central Baltic Sea herring, fishery management, Bayesian belief network, management scenario simulation, uncertainty communication.
\end{abstract}




\section{Introduction}

Uncertainty is an endemic condition of the Baltic Sea herring (Clupea harengus membras, L) fishery management. First of all, uncertainty is behind of the biological foundations of the management measures taken during the last decades. The scientific discussion on how best to establish the Baltic Sea herring assessment and management units in accordance with assumed different number of spawning components of this fish has been heated and many approaches have been taken over the years [1].

There is a number of studies published on the Central Baltic Sea herring recruitment-environment relationship $[2,3]$ and on substantial decrease in growth rate of the herring that has been observed since the beginning of the 1980s [4-6]. It is reported [7] that the decline in the Central Baltic Sea herring spawning stock biomass was partly caused by the reduction in mean weights-atage. The reduction in herring mean weight-at-age was likely induced by a decline in the herring's main zooplankton prey, which in its turn is believed to depend on increased food competition with sprat or a decline in the salinity of the Baltic [6]. Herring mean weights-at-age have stabilized since the late 1990s, but remain at a low level.

Despite of in-depth studies into the structure of the Baltic Sea clupeid fish otoliths [8] the ageing of these fishes is still far too uncertain. Considerable problems associated with difficulties in ageing of the Baltic Sea herring are being transformed into the uncertainty of the calculated fishing mortality $(F)$ and the year-class relative abundance estimates. Significant between-reader differences in ageing of the Baltic Sea herring are documented [9, 10].

The problem of the Baltic Sea herring's unaccounted fishing mortality caused by the fish selection through the trawl net has attracted attention of scientists and managers since 1990s [11, 12].

A review of recovery of the depleted Baltic Sea fish stocks, including the Central Baltic Sea herring, showed that for all internationally regulated fish stocks the Total Allowable Catches (TACs) have been set systematically more than the scientific advice based on sustainable exploitation [13]. Building on a language of Eagle and Thompson [14] it is interpreted as "decision overfishing" while the evidences of extensive underreporting of catches are interpreted as "implementation overfishing". Despite the measures that have been taken to combat the situation this still means that a management body was knowingly accepting a situation of overfishing.

It is stated [15] that the policy decisions on complex environmental risks often involve contested science and typically there are no 'facts' that entail a unique correct policy. Wardekker et al. [16] argue that communication of uncertainties aimed at policymakers, as well as other parties involved in policymaking, is important because uncertainties can influence the policy strategy that is selected while it is also a matter of good scientific practice, accountability and openness towards the general public. This is perfectly valid for the situation with fishery management. 
This paper attempts to address the main sources of uncertainty related to the management of the Central Baltic Sea herring fishery, including the herring in the Gulf of Finland. The Bayesian Belief Networks (BBNs) are used to communicate the major sources of uncertainty related to the management of the Central Baltic Sea herring fishery. Two scenarios for the Central Baltic Sea herring fishery management options are constructed and the Bayesian networks are used to represent and update uncertainties encountered in the process of the management related situation assessment. First scenario represents the current status of the fishery management resulting in fishing mortality higher than $\mathrm{F}_{\mathrm{MSY}}$ - the fishing mortality that corresponds to the Maximum Sustainable Yield (MSY). The second scenario demonstrates the assumed potential impact of economic incentives (e.g. zoning, individual transferable quotas (ITQs), territorial use rights etc.) on the reduction of excessive fishing capacity and bringing fishing mortality closer to $\mathrm{F}_{\mathrm{MSY}}$.

\section{Material and methods}

Conceptual model of the Central Baltic Sea herring stock management is developed using the Bayesian Belief Network (BBN) methodology [17] and the HUGIN RESEARCHER software. Converting a state of knowledge into a probability assignment is a problem that lies at the heart of Bayesian probability theory. The prior probabilities are obtained from the knowledge on the herring fishery management and the setting of conditional probabilities has been done externally based on the relevant published materials [18-20].

Interpretation of the probability statements expressed in this study is building on the notion of formally singular probability statement when it ascribes a probability to a single occurrence, or to a single element of a certain class of occurrences. Referring to objective interpretation of probability statements Popper defines the formally singular probability as follows [21]:

$$
\alpha P k(\beta)=\alpha F(\beta) \quad(k \in \alpha)
$$

This is expressed in words as: the formally singular probability that the event $k$ has the property $\beta$-given that $k$ is an element of the sequence $\alpha-$ is, by definition, equal to the probability of the property $\beta$ within the reference sequence $\alpha$. This means that only objective formally singular probability statement, when it ascribes a probability to a single occurrence, is empirically testable.

According to Popper [21] the subjective interpretation of probability statements about single events does not enable us to predict what the property of the event in question will be, but it enables us to express all we know about it by means of a formally singular probability statement - an indefinite prediction about the particular event in question. Author underlines: "I do not object [subjective interpretation of probability statements] ... so long as we clearly recognize that the objective frequency statements are fundamental, since they alone are empirically testable. I reject, however, any interpretation of those 
[subjective] formally singular probability statements - these indefinite predictions - as statements about the objective state of affairs, other than the objective statistical state of affairs".

Given a scenario of fishery management option, a Bayesian network depicts graphically the cause and effect relationship between various elements of the system concerned. In doing so it also demonstrates conditional dependence i.e., which factors are more relevant and directly affect a given output and which factors are less relevant in the sense that knowledge regarding these factors become redundant once the direct causes are known.

\section{Results and discussion}

\subsection{Uncertain science - uncertain management}

According to EU policy paper on fisheries management [22] the ICES classifies the Central Baltic Sea herring stock under the category 3 because it is fished outside safe biological limits [7]. In addition, the assessment of the Central Baltic Sea herring stock and the corresponding forecast are regarded by ICES to be acceptable although the accompanying uncertainties in underlying assumptions and data are critically influencing the quality of the fishing mortality estimates, including the quality of $\mathrm{F}_{\mathrm{MSY}}$ estimates.

\subsubsection{Stock assessment and management units}

Ojaveer and Kalejs [23] argue that the Baltic Sea different areas display marked differences in salinity, oxygen content and temperature of water layers, timing of the peak production cycle, and the other basic environmental conditions while the biota in the Baltic Sea has formed under wide variations in environmental conditions induced by the climate change since the last glaciations. It is suggested [24] that the Baltic Sea regions differ in essential environmental conditions and in the process of adaptation to their habitats, fishes like the Baltic Sea herring have developed local sub-species. Among marine exploitable fishes, spring spawning herring is the only species adapted to all regions of the Baltic Sea, forming 10 local populations. According to the latest studies by Jørgensen et al. [25] the Baltic herring can be divided into three genetically separated stocks: western, southern and northern stocks.

For the practical stock assessment reasons the Central Baltic Sea herring populations have been grouped by ICES for assessment purposes in different combinations over the period 1974-1990. Finally, the main reason for the creation of a large Central Baltic Sea herring assessment unit in 1990 (Subdivisions 25-29 and 32) was to try to eliminate the influence of migrations of herring in the Baltic Sea. Finally, the optimal solution was seen in seeking a reasonable compromise between biological knowledge and practical constraints set by the availability of data (lack of generally accepted routine method for separation of the herring sampled from the different local biological populations and lack of sufficient tuning data for assessment of the smaller stock units). 


\subsubsection{Effect of environmental trends}

Latest studies into the Central Baltic Sea herring recruitment-environment relationship [2] revealed as important stock recruitment predictors the temperature and the stock weight-at-age of the spawners. Moreover, the food supply is also considered as a significant predictor, suggesting that changes in climate and/or food web structure may indirectly affect herring recruitment via prey availability for the recruits or spawners.

Substantial decrease in growth rate of the Central Baltic Sea herring, attributed mainly to the changes in fisheries, trophic interactions and the climate, has been observed since the beginning of the 1980s [4-6]. In relation to the Gulf of Finland it is shown [26] that the long-term changes in the herring growth are correlated positively with salinity and with the abundance of the marine zooplankton species Pseudocalanus minutus elongatus. According to that study the density-dependent mechanism was not likely to explain the changes in herring weight-at-age in the Gulf of Finland while the strong negative correlation between herring weight and sprat biomass may indicate competition for food between these species.

According to ICES [7] the regional differences in the Central Baltic Sea herring growth rate result in a high proportion of small individuals in the North (SD 28.2, 29 and 32) and large individuals in the South (SD 25 and 26). At the same time the growth rate tends to change due to salinity variations and fluctuations in the herring stock and competition with the Baltic Sea sprat. Furthermore, the Central Baltic Sea herring stock dynamics is highly affected by cod predation.

Rahikainen and Stephenson [27] argue that the growth rates of herring in the northern Baltic Sea differ among areas, and have changed substantially over time in some areas in response to environmental change. It is stated that the growth variation has implications for stock assessment and management: differences suggest a need for considering a smaller spatial structure, at least at the scale of the ICES subdivision, in the case of northern Baltic herring, and the herring in different areas of the northern Baltic Sea probably require different reference points and possibly different management strategies, as a consequence of differences and variability in growth characteristics.

\subsubsection{Problems with ageing}

Main features of the Baltic Sea sprat and hering otoliths used for ageing of these fishes are discussed in literature [8]. However, Eklund et al. [9] are reporting the result of comparative ageing of the Baltic Sea herring from ICES Sub-division 29 where none of the comparisons between readers reached 50\% agreement and variations were considerable in old fish. It was further suggested that the variability of the age determinations should be taken into account as part of the data, and possibly incorporated as an error factor in, e.g., population assessments. It is stated [10] that "The actual importance of age variability in population modelling and fisheries management depends on the variability of other data used in the models, on the type of calculations, and also on the lines of management action that are considered. In Baltic herring, subject to the rapid 
changes in the ecosystem of the Baltic sea ... the imprecision of the age determinations constitutes a risk of misinterpreting biological signals both in fisheries management and in environmental monitoring". However, significant improvement was reported in 2008 when average agreement with the modal age of the Baltic Sea herring was on average $86.9 \%$ [28].

\subsubsection{Effect of fishing}

The problem of the Baltic Sea herring's unaccounted fishing mortality caused by the fish selection through the trawl net has been addressed in literature $[5,11$, and 12]. The survival experiments indicated that survival is positively linked to the size of the escapee. However, the most of the herring that escape die shortly after. Furthermore, the results reported by Rahikainen et al. [29] showed that the herring of the age group 0 and 1 are discarded underwater in larger numbers than landed while the actual fishing mortality at age 1 is estimated to be more than twice higher than its estimates based on the unadjusted data.

Raid [30] has analysed how equal are the "equal" catches in tonnes? Author showed that the equal herring catches in tonnes are resulting in considerably higher herring catches in numbers in the Gulf of Finland than in the open part of the Northern Baltic Sea. Indicator - the mean catch in numbers per 1000 tons of landings was proposed to communicate the possible spatial variability in the Baltic Sea herring fishing mortality.

ICES [7] states that the pelagic fisheries take a mixture of herring and sprat and this causes uncertainties in catch levels because the extent to which species misreporting has occurred is not well known. The recent trend to move fishing effort northwards results in high catches of small individuals.

According to Aps et al. [31] the performance of fishery management was evaluated using two indicators proposed by FAO [32]: the ratio of the agreed $\mathrm{TAC}$ and the recommended catch (TAC/tac) as the response indicator, which could be seen as a measure of decision overfishing; and the ratio of the actual catch and the recommended catch $(\mathrm{C} / \mathrm{tac})$ as the pressure indicator and the measure of implementation overfishing. In essence, indicator values $>1$ represent regulatory overfishing.

It is stated [13] that incomplete or missing advice from ICES from 1984-1989 and from 1992-1999 proved to have been a major obstacle to setting TACs for herring in Subdivisions 25-29 and 32 (excluding Gulf of Riga herring). Under conditions of a continuous decline in SSB, TAC have been set largely in excess of the advice $(0.98<\mathrm{TAC} / \mathrm{tac}<2.55)$. In addition, the officially recorded catches exceeded the recommended catches, with the exception of 1991, 2003, and 2004 $(0.73<\mathrm{C} / \mathrm{tac}<1.83)$. Although the $\mathrm{F}$ values have mostly been in excess of the Fpa, they dropped to this level in 2005, followed by a moderate increase in SSB (Figure 1, $a$ and $b$ ).

Because of unreliable catch statistics for the Baltic Sea sprat, fished as a mixture with herring, the ICES advice has been incomplete or missing in 1986, 1987, 1993, 1994, and 1997-1999 [13, 31]. In other years, the TAC largely exceeded recommended catches $(0.88<\mathrm{TAC} / \mathrm{tac}<2.44)$. The official catch statistics never exceeded the TAC and thus exceeded the recommended catch by 

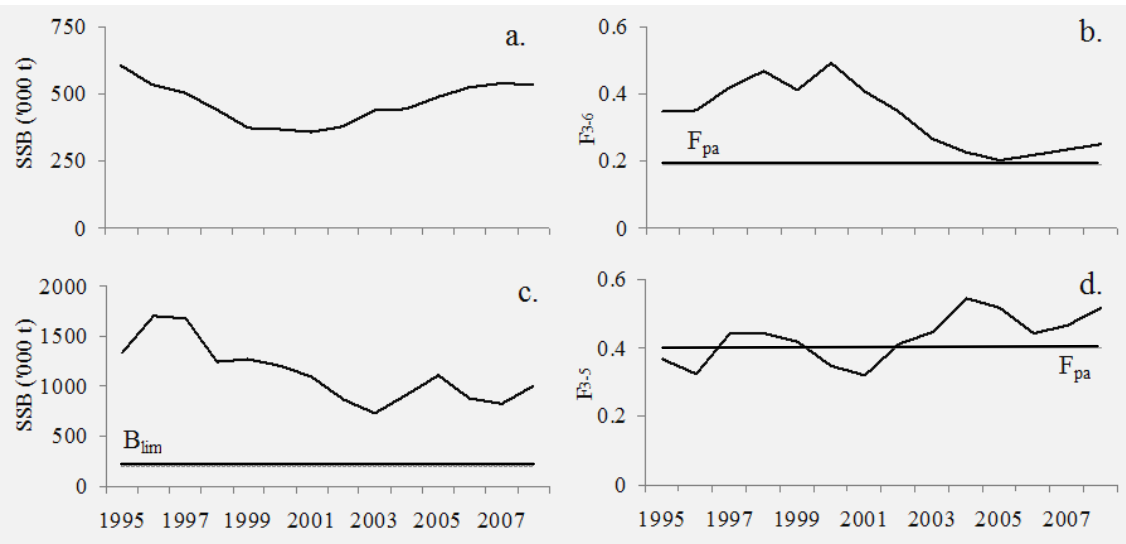

Figure 1: Annual estimates of SSB (left panels) and fishing mortality (F, right panels), 1995-2008, with indication of the limit (Blim) and precautionary (Fpa) reference points for ( $a$ and b) Baltic Sea herring (Subdivisions 25-29 and 32; excluding the Gulf of Riga; reference points agreed in 2002); and (c and d) Baltic Sea sprat (Subdivisions 25-32; Fpa operational since 2000) [13].

a smaller amount $(0.51<\mathrm{C} /$ tac $<1.90)$. F has constantly exceeded Fpa since 2002, while the SSB have always been above Blim (Figure 1, c and d).

\subsection{Central Baltic Sea herring fishery management: Bayesian uncertainty communication}

\subsubsection{Bayesian model of fishery management}

$\mathrm{BBN}$ is constructed to assess a variety of situations that are likely to be generated by the different fishery management scenario options. Attempt is made to communicate the relationship between the fishing fleet capacity, the public pressure and the level of fishing mortality in relation to $F_{\text {MSY }}$. This BBN network (Figure 2) contains two information variables: 1) "Flet capacity" (fishing fleet capacity is balanced/not balanced with the fishery resources available), 2) "Public pressure" (reasoning in support of sustainable fishing strong/weak), and one hypothesis variable - "Harvest" (fishing mortality is less or equal to the $\mathrm{F}_{\mathrm{MSY}} /$ fishing mortality exceeds the $\mathrm{F}_{\mathrm{MSY}}$ ) that is presenting the one yearly cycle of the fishery activities. The rest are intermediate nodes ("Control and enforcement" and "TAC decision" that help propagate evidence from the information variables to the hypothesis variable.

Let $X$ be a discrete random variable taking the values $\left\{x_{1}, \ldots, x_{n}\right\}$ representing our current knowledge. If our current state of knowledge is total ignorance then we will not be able to distinguish between various alternatives and this leads to the uniform probability distribution $P\left(x_{1}\right)=1 / n$. Thus, we assign a probability distribution to our hypotesis variable such that all its possible values are equally probable. 
After the network has reached an equilibrium with these initial conditions we instantiate both information variables to their corresponding evidence values according to scenario presenting the recent state of affairs.

In order to simulate the current status of the fishery management the "Fleet capacity" is instantiated as "Not balanced" with the fishery resources available. According to the opinion of the European Court of Auditors [20] the "[Recent] overcapacity is a factor in over-fishing. It influences the behavior of the industry and the legislator, by reducing the profitability of enterprises in the sector, which have to bear the costs associated with the overcapacity of their means of production. The fishing industry is exposed to the temptation of exploiting its over-sized vessels to the full and to fish beyond the authorised limits. There is a risk of underdeclaring of their catches or throwing the less profitable part overboard". The variable "Public pressure" is instantiated as being weak based on the Baltic Sea Regional Advisory Council (BS RAC) performance [18, 19].

As a result, it is seen that the actual fishing mortality of the Central Baltic Sea herring is higher than $\mathrm{F}_{\mathrm{MSY}}$ and the harvest is believed to be not sustainable. Furthermore, the value of the calculated $\mathrm{F}_{\mathrm{MSY}}$ is quite uncertain e.g. just because of the insufficient quality of the catch data. European Court of Auditors [20] states that the incompleteness and unreliability of catch data prevent the TAC and quota system, which is a cornerstone in the management of Community fisheries resources, from functioning properly while the regulatory framework and the procedures in force guarantee neither the exhaustiveness of data collection, nor the detection of inconsistencies during validation.

The states of the intermediate nodes "Control and enforcement" and "TAC decision" agree with the published information. It is stated [20] that "... the effectiveness of inspection and control systems is impeded by the existence of a very high inherent risk associated with the existence of significant fishing overcapacity."

State of the "TAC decision" node is also in accordance with the opinion of the European Court of Auditors [20]: "When the Council of Ministers adopts the TAC and quotas it acts as an arbiter between divergent short-term interests, environmental on the one hand, and socio-economic on the other. In doing so it may authorize catch quantities that are higher than those recommended by the scientists, in order to protect the immediate social and economic interests of those employed in the industry. Furthermore, the Council's choices are made without any means of evaluating objectively how the catch levels will impact on any of those interests".

The posterior probabilities get calculated when the network reaches equilibrium again and we use these to demonstrate this scenario related uncertainty (Figure 2).

For the first year the hypothesis variable "harvest_1" is showing that fishing mortality exceeds the $F_{\text {MSY }}$ and this corresponds to the ICES latest assessment [7]. If no changes in economic incentives occur then the overfishing will most probably continue also during the second year of simulation.

Scenario that simulates the impact of strong economic incentives to reduce the fishing fleet capacity is presented in Figure 3. 


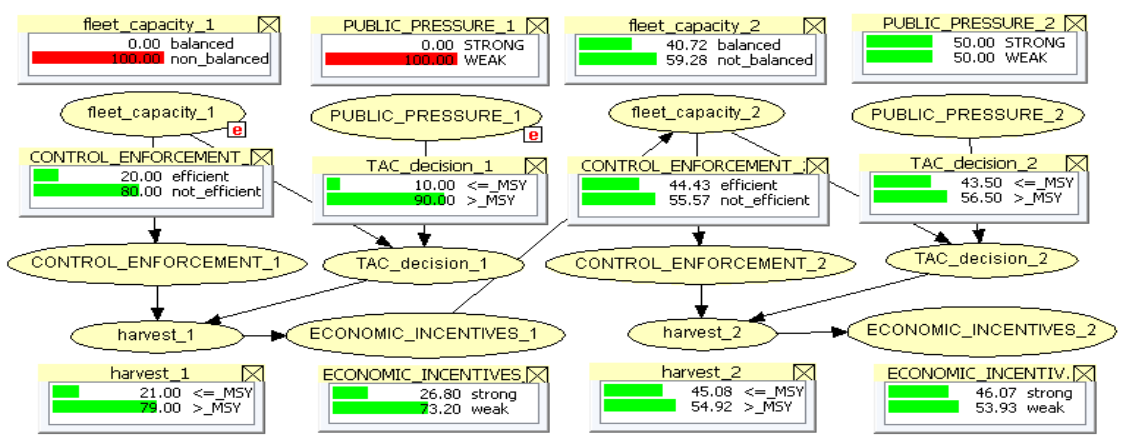

Figure 2: $\quad \mathrm{BBN}$ representing the state of the knowledge for the current status of the Central Baltic Sea herring fishery management.

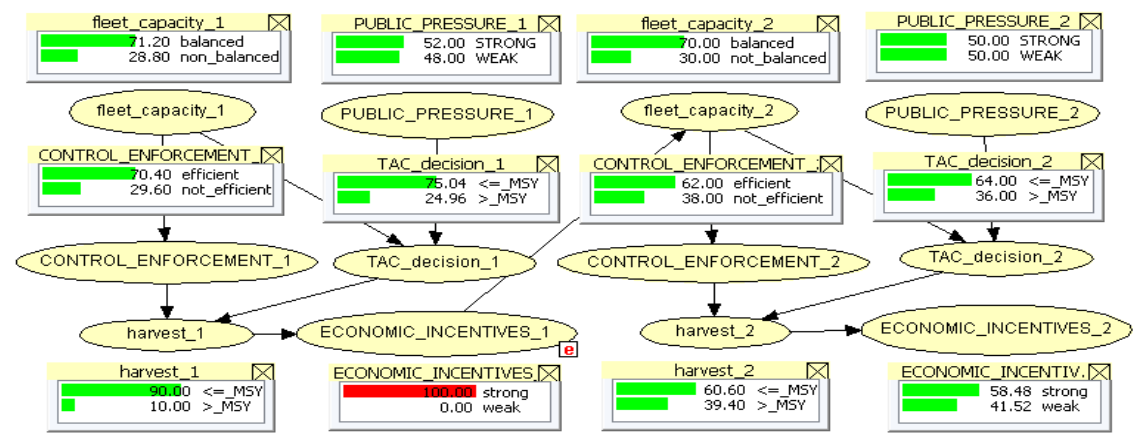

Figure 3: $\quad \mathrm{BBN}$ representing the scenario with strong economic incentives to reduce the fishing fleet capacity in the Central Baltic Sea herring fishery.

The node "Economic incentives" is instantiated as being "Strong", and as a result the fishing fleet capacity is expected to be in a state "Balanced" with the fishery resources available. By virtue of that, it is expected that the control and enforcement, TAC decisions and public pressure will improve finally resulting in the actual fishing mortality value moving closer to the $\mathrm{F}_{\mathrm{MSY}}$ value.

Traditional fishery management system is by its nature based on command and control with the regulator accepting most of the responsibility for management while rights based management rely much more on self-interest. Scott [33] states that "There are three general powers of ownership: to manage the asset, to transfer or sell it, and to take the income from it. The [Individual Transferable Quota] ITQ certainly gave the fisherman the third power. Instead of merely allowing him to go out and compete with others until the TAC was reached, it entitled him to a definite fixed percentage of the TAC - that is to the yield itself." The substantial body of published evidences shows that with openaccess, non-exclusive fishing rights, too many resources are concentrated into 
fishing. It is believed that the ITQ system remarkably improves the allocation of resources because the fishing right-holders have a greater vested interest in the resource and are better motivated to take more responsibility for management.

\section{Conclusions}

Bayesian network simulation of the Central Baltic Sea herring fishery management is used to communicate the major sources of uncertainty in the system. This simulation shows that the fishing fleet overcapacity is the most important driver behind the decision and implementation overfishing and the related uncertainty. The environmental trends are influencing first of all the stock-recruitment relationship and the weight-at-age of the herring and they are contributing this way to the uncertainty of the calculated fishing mortality and the $\mathrm{F}_{\mathrm{MSY}}$. It is shown that assumed implementation of the strong economic incentives to reduce the fishing fleet capacity would bring the actual fishing mortality closer to the $\mathrm{F}_{\mathrm{MSY}}$ value.

\section{Acknowledgements}

We thank Dr. Tiit Raid for his constructive comments. This study was supported by the Estonian Science Foundation grant No.7609, Estonian target financing program SF0180104s08 and by the Baltic Organizations Network for Funding Science EEIG (BONUS+) Project IBAM "Integrated Bayesian risk analysis of ecosystem management - Gulf of Finland as a case study".

\section{References}

[1] Aps, R. Management of shared Baltic fishery resources. In: Management of Shared Fish Stocks. Ed. by A. I. L. Payne, C. M. O'Brien, and S. I. Rogers. Blackwell, Oxford, pp. 190-201. 2004.

[2] Cardinale, M., Möllmann, C., Bartolino, V., Casini, M., Kornilovs, G., Raid, T., Margonski, P., Grzyb, A., Raitaniemi, J., Gröhsler, T., Flinkman, J. Effect of environmental variability and spawner characteristics on the recruitment of Baltic herring Clupea harengus populations. Mar. Ecol. Prog. Ser. Vol. 388, pp. 221-234. 2009.

[3] Margonski, P., Hansson, S., Tomczak, M.T., Grzebielec, R. Climate influence on Baltic cod, sprat, and herring stock-recruitment relationships. Progress in Oceanography, 87, pp. 277-288. 2010.

[4] Horbowy, J. Growth of the Baltic herring as a function of stock density and a food resources. Acta Ichthyologica et Piscatoria, Vol. XXVII (1), pp.2739. 1997.

[5] Raid, T., Järvik, A. Baltic herring fisheries management in Estonia: a biological, technical, and socioeconomic approach. In: Herring: expectations for a New Millennium. Alaska Sea Grant College Program, AK-SG-01-04, pp. 703-720. 2001. 
[6] Casini1, M., Bartolino, V., Molinero, J.C., Kornilovs, G. Linking fisheries, trophic interactions and climate: threshold dynamics drive herring Clupea harengus growth in the central Baltic Sea. Mar. Ecol. Prog. Ser. Vol. 413, pp. 241-252. 2010.

[7] ICES. ICES Advice 2010, Book 8, pp. 21-28. 2010.

[8] Aps, R., Ustinova, L., Gentzen, B., Grygiel, V., Paat, A., Uder, Y.-O., Fetter, M., Groth, B., Kestner, D., Wyshinski, M. Guide for the use of Baltic sprat and herring otoliths in fisheries studies. Fischerei-Forschung, 29 (Sonderheft), Rostock, 42 p. 1991.

[9] Eklund, J., Parmanne, R., and Aneer, G. Between-reader variation in herring otolith ages and effects on estimated population parameters. Fisheries Research, 46, pp. 147-154. 2000.

[10] Peltonen, H., Raitaniemi, J., Parmanne, R., Eklund, J., Nyberg, K., Halling, F. Age determination of Baltic herring from whole otoliths and from neutral red stained otolith cross sections. ICES J. Mar. Sci., 59, pp. 323-332. 2002.

[11] Suuronen, P., Erickson, D.L., Orrensalo, A. Mortality of herring escaping from pelagic trawl codends. Fish. Res. 25, pp. 305-321. 1996.

[12] Suuronen, P., Perez-Comas, J.A., Lehtonen, E., Tschernij, V., Size-related mortality of herring (Clupea harengus L.) escaping through a rigid sorting grid and trawl codend meshes. ICES J. Mar. Sci., 53, pp. 691-700. 1996.

[13] Aps, R., Lassen, H. Recovery of depleted Baltic Sea fish stocks: a review. ICES J. Mar. Sci., 67, pp. 1856-1860. 2010.

[14] Eagle, J., and Thompson, B. H. Answering Lord Perry's question: dissecting regulatory overfishing. Ocean and Coastal Management, 46, pp. 649-679. 2003.

[15] Van der Sluijs J.P., Petersen, A.C., Janssen, P.H.M., Risbey, J.S., Ravetz, J.R. Exploring the quality of evidence for complex and contested policy decisions. Environ. Res. Lett., 3 (2), pp. 1-9. 2008.

[16] Wardekker, J.A., van der Sluijs J.P., Janssen, P.H.M., Kloprogge, P., Petersen, A.C. Uncertainty communication in environmental assessments: views from the Dutch science-policy interface. Environmental Science \& Policy, 11, pp. 627-641. 2008.

[17] Jensen, F.V., Nielsen, T.D. Bayesian Networks and Decision Graphs. Springer, 448 p. 2007.

[18] http://www.bsrac.org/ooizzCMS/DA/statementsandrecommendations.

[19] Aps, R., Fetissov, M., Kell, L, Lassen, H. Baltic Sea Regional Advisory Council as a hybrid management framework for sustainable fisheries. In: C.A. Brebbia, E. Tiezzi (Eds.). Ecosystems and Sustainable Development. UK: WIT Press, pp. 163 - 172. 2009.

[20] ECA. The European Court of Auditors' Special Report No 7/2007 on the control, inspection and sanction systems relating to the rules on conservation of Community fisheries resources, 71 p. 2007.

[21] Popper, K. The logic of scientific discovery. Routledge, London \& New York, 513 p. 2009. 
[22] EC. Communication from the Commission: consultation on fishing opportunities for 2011. COM(2010) 241 final, 20 p. 2010.

[23] Ojaveer, E., Kalejs, M. The impact of climate change on the adaptation of marine fish in the Baltic Sea. ICES J. Mar. Sci., 62, pp. 1492-1500. 2005.

[24] Ojaveer, E., Kalejs, M. On ecosystem-based regions in the Baltic Sea. Journal of Marine Systems, 74, pp. 672-685. 2008.

[25] Jørgensen, H.B.H., Hansen, M.M., Bekkevold, D., Ruzzante, D.E., Loeschke, V. Marine landscapes and population genetic structure of herring (Clupea harengus L.) in the Baltic Sea. Molecular Ecology 14, pp. 32193234. 2005.

[26] Rönkkönen, S., Ojaveer, E., Raid, T., Viitasalo, M. Long-term changes in Baltic herring (Clupea harengus membras) growth in the Gulf of Finland. Can. J. Fish. Aquat. Sci. 61(2), pp. 219-229. 2004.

[27] Rahikainen M, Stephenson R.L. Consequences of growth variation in northern Baltic herring for assessment and management ICES J. Mar. Sci. 61 (3), pp. 338-350. 2004.

[28] ICES. Report of the Workshop on Age Reading of Baltic Herring (WKARBH). ICES CM 2008/ACOM: 36, 37 p. 2008.

[29] Rahikainen, M., Peltonen, H., Pönni, J. Unaccounted mortality in northern Baltic Sea herring fishery-magnitude and effects on estimates of stock dynamics. Fisheries Research 67, pp. 111-127. 2004.

[30] Raid, T. On the effect of fishery on herring stocks in the North-Eastern Baltic. ICES, Baltic Fish Committee, C.M. 1996/J:27. 16 p. 1996.

[31] Aps, R.; Kell, L.; Lassen, H.; Liiv, I. Negotiation framework for Baltic fisheries management: striking the balance of interest. ICES J. Mar. Sci., 64(4), 858 - 861. 2007.

[32] FAO. FAO. Indicators for sustainable development of marine capture fisheries. FAO Technical Guidelines for Responsible Fisheries: 8.68 pp. 1999.

[33] Scott, A. Introducing Property in Fishery Management, pp. 1-13. In: R. Shotton (ed.). FAO Fisheries Technical Paper 404/1. Use of Property Rights in Fisheries Management. Proceedings of the FishRights99 Conference, Fremantle, Western Australia 11 - 19 November 1999, Rome. 2000. 